\title{
EL AMPARO EN LA CONSTITUCION DE 1979
}

Alberto Borea Odría

\section{A : Domingo García Belaúnde, mi maestro}

Es el Amparo una de las instituciones que se incorpora como tal a la vida constitucional del Perú en la Carta de 1979.

Los derechos fundamentales que la Constitución reconocía a los ciudadanos de la República, fueron garantizados en la Constitución de 1933 a través del Habeas Corpus. Este instituto, como se sabe, fue ideado para la defensa del derecho de libertad individual(1). Con posterioridad y debido a la necesidad de cautelar también los nuevos derechos sociales, distintos en su concepción y diferentes en su concreción a los derechos individuales de la formación liberal, los juristas debieron crear una nueva figura que se adaptase a las necesidades y que cumpiese con garantizar su vigencia cuando fueren atacados o violados.

Esta nueva garantía fue el Amparo. No obstante, su incorporación al constitucionalismo no ha sido rápida. En algunos paises ha sido la jurisprudencia la que lo ha impulsado a la categoría de institución cautelar arbitrándole incluso, por falta de normas procesales preexistentes, un camino propio, como en el caso de Argentina(2).

El Perú siguió manteniendo hasta 1968 como única garantía constitucional contra la violación de todo tipo de de rechos constitucionales al Habeas Corpus tal como fuera legislado en el Código de Procedimientos Penales de 1940, (artículos 349 y siguientes), destinado en su intención a la defensa de los derechos estrictamen te individuales como son la libertad personal, el derecho de libre tránsito o el de permanencia en el territorio de la República.

Con anterioridad a esa fecha ya Raúl Ferrero Rebagliati, por ejemplo, se había pronunciado acerca de la conveniencia de legislar sobre el Amparo. La raźón fluía del análisis de la jurisprudencia y de la propia constatación acerca de la inaplicabilidad, por múltiples razones, de las normas procesales del Habeas Corpus a la defensa de derechos como el de propiedad o el de la libertad de reunión. Ei Habeas Corpus es una vía sumarísima en la que basta sólo una constatación de la veracidad o falsedad del ataque al derecho individual ¿Cómo conjugar esto con una defensa del derecho de propiedad por una discusión acerca del justo precio de una expropiación? En este segundo caso el Estado tiene un

(1) Ver Sánchez Viamonte, Carlos: "El Habeas Corpus". Ed. La Ley 1924 o García Belaúnde, Domingo "El Habeas Corpus en el Perú". Ed. U.N.M.S.A., Lima 1979.

(2) Véase Housay, Abel. 
derecho a contestación y existe una materia sujeta a interpretación en la que al haber discutibilidad hay la obligación de entablar contienda.

El Decreto Ley 17083, introdujo en el Perú un camino procesal distinto al establecido para la tramitación del Habeas Corpus para aquellos casos en que la violación fuere la de un derecho distinto al de libertad personal, inviolabilidad de domicilio y libertad de tránsito. Se señaló que serian las salas civiles las que, fuera de los casos reseñados, se encargarían de la vista de las causas y se incorporó el principio de la contestación por parte del organismo responsable de la presunta violación.

Era sin duda un avance, no obstante se le siguió llamando Habeas Corpus a este nuevo proceso y dado lo exiguo de su articulado el Código de Procedimientos Penales siguió siendo norma complementaria.

La constitucionalización del Amparo era precisa. Fuera de Ferrero Rebagliati, Domingo García Belaúnde(1) y el propio autor(2) habían solicitado esta medida.

En materia de garantías constitucionales, la nueva Carta Política no sólo es más ordenada que la anterior por cuanto separa y distingue acertadamente lo que son los derechos "atribuciones, facultades que se otorgan a los individuos que conforman la población del Estado"(3) de lo que son las garantías: "instrumento procesal con que se arma al individuo para que pueda tener a su alcance inmediato el medio de hacer efectivo cualquiera de los derechos que constituyen en conjun to la libertad civil y política"(4).

La Constitución de 1979 le ha dedicado el título V a las Garantías Constitucionales, pero, además, la nueva Constitución recoge ya dife renciadas a la acción de Habeas Corpus y a la acción de Amparo (artículo 295), no obstante el tratamiento no es acabado y se precisarán una serie de normas complementarias o leyes orgánicas en que se definan con claridad cada uno de estos institutos.

Analicemos a continuación el nuevo texto:

En primer lugar, acepta que la violación al derecho constitucional se debe reparar tanto si la agresión proviene de un acto positivo (comisión), o de la negación de un acto (omisión). Era claro que en todo caso siempre se han podido

(1) García Belaúnde, Domingo: “E1 Habeas Corpus Interpretado” Ed. Pontificia Universidad Católica, Lima 1971.

(2) Borea Odría, Alberto: "La defensa constitucional: el Amparo". Ed. Biblioteca Peruana de Derecho Constitucional, Lima 1977.

(3) Sánchez Viamonte, Carlos: Ob. cit., pág. 21.

(4) Bidart Campos, Germán J. "Derecho Constitucional". Ed. Edia Bs. As. I-II Pág. 65. 
violar las normas juridicas por acción o por omisión, por ejemplo, cuando un funcionario se niega a darle el visado correspondiente a un pasaporte de un ciudadano peruano en el extranjero. La Constitución de 1933 no era en estos términos clara y resulta un avance lo preceptuado por el nuevo texto.

En segundo término, al señalar que el Amparo "cautela los demás de тechos reconocidos en la Constitución", la Constitución acepta que esta garantía sirva para proteger derechos de muy diverso contenido y que exigirán a la Ley Orgánica arbitrar una serie de caminos procesales para que, urgente y eficazmente, se pueda llegar a solucionar las violaciones.

A nadie puede escapar el hecho que la protección del derecho de propiedad tiene que ser regulada de distinta manera al de libertad de reunión y ambos a cualquiera de los de rechos sociales, siempre que se entienda, y esto lo veremos más adelante, que las garantías deben cautelar este especial tipo de normas. En el primero de estos casos se puede proceder a una suspensión del acto reclamado en tanto se discute el derecho del agresor y del agredido, la discusión no perjudicará en este caso el derecho. En el segundo, si la discusión se prolonga en los términos normales el fallo puede devetiir en ilusorio y el triunfo procesal del quejoso no irá más allá de una victoria pírrica puesto que, por ejemplo, solicitado un permiso para una manifestación pública el último día de campaña electoral y denegado arbitrariamente el permiso aún con los sumarios términos de la acción de garantía, la resolución sería dada con posterioridad a la elección y, por imposibilidad de reparación del daño, tendría que declararse sin materia sobre la cual resolver.

Esto se conjuga con el tercer párrafo del mismo artículo 295o. que insiste en la falla en tanto supone una similitud entre el Habeas Corpus y el Amparo en materia procesal. Ya hemos señalado por qué no pueden tener el mismo trámite $y$ en un artículo tan corto es imposible insidir sumamente en ello.

Debe entenderse, en todo caso el texto constitucional, como el deseo de los constituyentes de darle un trámite sumarísimo al Amparo y, en tanto no se sancione la ley orgánica de procedimientos constitucionales, las normas vigentes de Habeas Corpus pueden ser consideradas supletorias.

Otra de las necesarias precisiones que se encuentran consignadas en el texto es aquella que establece que no sólo procede la utilización de la garantía cuando la agresión proviene de una autoridad política sino también en los casos en que es un particular el que agrede el derecho constitucional ajeno. La doctrina está dividida en este pun to por cuanto quienes pensaban que sólo debía proceder el Amparo cuando se trataba de agresión por parte de funcionarios sustentaban su posición en razones históricas (la garantía y en especial el Habeas Corpus se generan en la necesidad de defender el derecho de los particulares contra el abuso de autoridad), y en razón que podrímos denominar como práctica puesto que para la agresión de quien no actúa en nombre del Estado podrían 
utilizarse las normas comunes del Código Penal(*). Por el contrario, los que se inclinan por la procedencia del Amparo para los casos en que la agresión proviene de particulares, se amparan en que lo importante no es quien comete la agresión, sino que se ha dado una violación de la Constitución en perjuicio de un ciudadano, que esos derechos son de fundamental importancia y que lo principal no es castigar al infractor, sino restituir al agredido en el goce de su estatuto jurídico $(* *)$.

Por otra parte, si bien en la época liberal prácticamente desaparecieron las instituciones intermedias entre el hombre y el Estado, en el momento presente no puede explicarse la sociedad con prescindencia de las asociaciones, clubes, sindicatos, confederaciones, colegios profesionales, partidos políticos., todos los cuales tienen un rol importante en la vida del individuo quien muchas de las veces centra su propia vida en su participación en estas instituciones $y$, por tanto, pone un poco su destino a su merced. Este poder debe ser prontamente controlado cuando, rebasando su natural cauce, agrede el Derecho Constitucional y en especial los derechos constitucionales de las personas.

Nuestra anterior Constitución de 1933 no precisó este punto, no obstante cabe mencionarse que al tiempo de ser promulgada el Código de Procedimientos en Materia Criminal(***), vigente-entonces, señalaba la procedencia del Habeas Corpus en estos casos. Al reformarse el Código se modificó la nerma que asílo entendía y la jurisprudencia casi unánimente se ha resistido a aceptar este principio de la procedencia del amparo en el caso de violación por parte de los particulares.

Parécenos, un acierto la incorporación de este principio por las razones expuestas que hemos suscrito en anterior trabajo ya citado.

Otro de los puntos que parece quedar claro del propio texto es aquel deslinde entre la acción de garantía en sí y el castigo al causante de la infracción constitucional. En varias oportunidades en este mismo artículo hemos mencionado que lo esencial ya del amparo o del Habeas Corpus es la de fensa del derecho. Sin embargo, la jurisprudencia en el Perú consideró como un todo indesligable la propia garantía y el castigo al infractor, deshechando muchas veces la acción por la falta de designación del nombre del presunto culpable de la agresión a efectos de la aplicación de la sanción. Esta confusión nacia del artículo 356 del C.P.P.

Cabe mencionarse que son los puntos teóricos que el texto ha aclarado convenientemente: la procedencia del Amparo para violación por omisión, la

* Entre estos autores están Domingo García Belaúnde y Rafael Bielsa.

** Entre estos están José Larrami, Angel Flor Brice, Germán Bidart, Antonio Carrillo Flórez.

*** Ard. 
procedencia del Amparo contra las amenazas de violación, la procedencia del Amparo cuando el ataque le es debido a los particulares.

Hay 2 otros que no están debidamente aclarados. Cuando la agresión se basa en una ley inconstitucional y cuando proviene de una resolución judicial.

Se ha sostenido reiteradamente que lo importante es la defensa del derecho constitucional y no la categor ía del agresor. ¿Qué sucede cuando esta violación o amenaza se sustenta en una norma legal? El problema suscita mayores comentarios y es preciso no ahorrar esfuerzos en clarificar este punto.

La ley, en primer término, tal como lo sostiene Raúl Ferrero en su libro Ciencia Política, tiene presunción de validez y legitimidad. Es o se dice que es la expresión del deseo de regulación por parte del detentador del poder y si éste se basa en un sistema democrático se señala que es la voluntad de la mayoría del pueblo la que apoya la norma. ¿Puede contra esto revelarse un hombre? Naturalmente que este punto se encuentra en estrecha relación con el de los derechos de la minoría.

Domingo García Belaúnde sostiene en su libro "El Habeas Corpus en el Perú" que "éste no debía usarse para impugnar normas ni mucho menos defender el principio de la soberanía de la Constitución " (ver libro citado p; 117). Entre las razones que consigna hay algunas de carácter jurídico general y otras de evolución histórica del derecho peruano. Entre las primeras menciona lo que considera ser su esencia. la defensa contra actos arbitrarios desprovistos de toda normatividad. Traemos a colación esta opinión en el presente trabajo en tanto que perteneciendo el Habeas Corpus y el Amparo a la familia de las garantías, los rasgos doctrinales de ambas instituciones son comunes.

No compartimos sin embargo esa opinión. Aceptar esta posición sería dejar al desamparo a todos los ciudadanos frente a las decisiones de la autoridad, con el agravante que en nuestros países el sistema de designación de autoridades no es estable ni regular y que, de primar este temperamento, bastaría con una norma cualquiera emanada del circunstancial detentador del poder para dejar sin efecto cualesquiera precepto de la Constitución. Esto se agrava aún más si se tiene por sentado que el criterio de la no justificabilidad de los llamados actos políticos es doctrina aceptada por la jurisprudencia de nuestros paises y que no se discute en estos casos la inconstitucionalidad por origen de las normas (análisis de la legalidad de quien la promulga) sino la inconstitucionalidad por destino (análisis de las disposiciones del propio texto legal). Por ejemplo, si se aceptara este temperamento cualquier tirano o dictador -en la connotación actual del término-, podría darle forma de ley a un atropello y convertir en indiscutible la agresión en el momento de su comisión.

A esto se puede, no obstante, levantar dos objeciones. La primera, que la discusión se podría dar en el campo de una acción ordinaria, pero creo que en este punto estaremos de acuerdo en que lo lato del procedimiento podria hacer 
devenir en irreparable el daño causado a la victima de la agresión. La segunda, más de fondo, una discusión acerca del porqué de la primacía constitucional sobre todas las demás normas. En este punto Carl Schmitt, manifiesta que: "en el Estado legisłativo, el legislador es siempre uno, el legislador sin más. Toda concurrencia de legisladores de distinta categoría (entre los que estarían los constituyentes) y de conceptos de ley relativizados entre si (entre los cuales estaría la constitución) destruye, como ya se ha subrayado el Estado Legislativo" (Legalidad y Legitimidad. Ed. Aguilar, 1971 p. 29) y si no existe esta preeminencia carece de objeto discutir sobre la procedibilidad del Amparo. No obstante, el mundo moderno, especialmente a partir del caso Marbury vs. Madison, fallado por la Corte Suprema de los Estados Unidos, ha ido aceptando, ya sea por lo que se ha llamado un control difuso (tribunales ordinarios en cualquier acción); control concentrado (tribunales especiales o tribunal especial), el análisis de la constitucionalidad de las leyes.

En el Perú, esta supremacía de la Constitución sobre las leyes, expresada clara e inequivocamente en el texto constitucional es también una de las innovaciones de la Carta de 1979, ya que en el artículo 87 dice: "La Constitución prevalece sobre toda otra norma legal'.

La discusión luego de este texto se reduce a apreciar si en el procedimiento de Amparo puede o no discemirse la constitucionalidad o inconstitucionalidad de un acto que motiva la acción.

A la opinión de Domingo García Belaúnde se le suma la de Enrique Chirinos Soto, Constituyente, que en sus comentarios a la Constitución, publicado bajo el título "La Nueva Constitución al alcance de todos" dice que: "el habeas corpus y la acción de amparo no se intentan contra resoluciones como tales, sino frente a casos concretos de violación de derechos constitucionales" (ver libro citado pág. 356). El Maestró Héctor Fix Zamudio nos documenta en su libro "Veinticinco años de evolución de la justicia constitucional 1940-1945" (Ed. U.N.A.M. México 1968), en cuanto precisa que en el sentido casi generalizado de la legislación comparada es el de no aceptar por la vía del Amparo la discutibilidad de la constitucionalidad de un precepto legal.

El Art. 236 de la actual Constitución dice que: "En caso de incompatibilidad entre una norma constitucional y una legal ordinaria, el Juez prefiere la primera...". Aquí no hay ninguna diferenciación entre los procesos que se siguen. Aquí sólo se habla que en el caso de incomptabilidad entre una norma constitucional y otra legal el puez debe de preferir la primera. Vale decir que éste es un precepto imperativo para el Juez. Ningún juez podrá alegar siquiera, que la inconstitucionalidad no es deducida por las partes puesto que es principio de la hermenéutica jurídica que el Juez conoce el derecho. Y si nó se hace aquí esta distinción, ¿puede distinguirse donde la ley no distingue? ¿No es caso el amparo una acción tal como lo reconoce la propia Constitución en su Art. 295? ¿Acaso se precisa de tiempo probatorio especial para apreciar la inconstitucionalidad de una norma? ¿No es esto último un proceso deductivo que no exige otra cosa 
que el raciocinio de los magistrados?

Por otro lado, la acción de inconstitucionalidad que se menciona en el art. 298 del texto fundamental es distinta a la excepción de inconstitucionalidad, que en realidad comporta la oposición de esta categoría a cualquuier juez en la sustentación de dicha garantía, lo que interesa es el cese de la violación en el caso concreto y el juez no puede administrar justicia prescindiendo del más importante instrumento jurídico del pais. En cuanto a la acción de inconstitucionalidad encargada al Tribunal de Garantías Constitucionales, esta sí decidirá para todos los casos e importará la derogatoria de la norma cuestionada.(Art. 301).

Creo pues, que a pesar de las opiniones del Dr. Chirinos, uno de los Constituyentes, así como las versadas apreciaciones del Dr. García Belaúnde, el Amparo en el Perú de 1980 puede ser intentado aún cuando la agresión venga basada en una ley inconstitucional. Importaria sí, aclarar este punto en la ley orgánica de garantías a efectos de evitar dobles interpretaciones.

Con respecto al amparo contra las resoluciones judiciales atentatorias del derecho constitucional, la nueva Constitución tampoco ha hecho un pronunciamiento taxativo.

Naturalmente que no puede haber duda en tanto la agresión provenga de un miembro del Poder Judicial que no tenga jurisdicción o competencia alguna, puesto que en este caso estamos ante un hecho abusivo, ilegal y corriente y no hay autoritas, ni respaldo del órgano jurisdiccional como tal.

La discusión surge en cuanto a que la agresión fluya del propio proceso, ya sea en la parte sustantiva, ya en la procesal. El Art. 295 segundo párrafo señala que la procedencia se da en los casos en que la agresión venga de cualquier funcionario, y los miembros del organo jurisdiccional son funcionarios por lo que también puede comprendérsele a ellos y a sus actos.

La tarea que debe desarrollar la jurisprudencia del Tribunal de Garantias Constitucionales será muy importante, sin embargo, para evitar que todo litigante vencido prenteda sin razón utilizar el recurso de amparo. Este ha de tener carácter extraordinario.

Quedan finalmente por tocar dos puntos que deberán de contemplarse en la ley orgánica respectiva:

a. La suplencia de la queja, vale decir, la facultad del Juez para remediar cualquier falla procesal que pudiera entorpecer la continuidad de la acción. En el Perú se han dado casos en que la falta de una fotocopia o la de una Partida, han motivado la nulidad de todo el proceso. Con razón dijo Felipe Tena Ramírez refiriéndose al amparo mexicano, que las formalidades con que la ley rodea al amparo de estricto derecho, los numerosos y a veces injustificados requisitos que debe satisfacer el quejoso en esta clase de 
Amparo so pena de no alcanzar justicia, significan para él una trampa y para el Juez una burla. Los quejosos que no dominan los secretos de este juicio esotérico, y son casi todos, o los que no pueden contratar abogados especialistas en la materia, y son los más, se juegan al azar del destino su causa, y cuando en los pleitos cuantiosos se enfrentan abogados de nota, el Amparo de estricto derecho suele ser también un fracaso, porque se convierte en dédalo donde con frecuencia sale mejor librada la habilidad que la justicia" (Tena Ramírez, Felipe: "El Amparo de Estricto Derecho" en revista de la Facultad de Derecho de la UNAM 1954 T. IV. p. 9).

b. La suspensión del acto reclamado; que garantiza al quejoso de no ser perjudicado por la continuidad de una acción que puede ser declarada inconstitucional. Dada la prontitud de los términos esto debe ser indispensable.

La ley orgánica deberá tratar también puntos como el de la personería para la interposición de la acción y otros que se comentarán más detalladamente en otro trabajo y que no es posible hacerlo en éste dada las limitaciones de espacio a que se nos ha confinado.

El Amparo, incorporado al ordenamiento procesal constitucional, llena un vacío en la defensa de los derechos del hombre. Su sola inclusión no garantiza su cumplimiento. Los jueces deberán darle el soplo de vida real del cual precisan.

Lima, Julio de 1980

Alberto Borea Odría 